\title{
IDENTIFICATION AND SELECTION OF SIX SIGMA PROJECTS
}

\author{
Abdalhkeim FA. Flifel, ${ }^{1}$ Nebojša Zakić, ${ }^{2}$ Aleksandra Tornjanski ${ }^{3}$ \\ ${ }^{1}$ Business and Law Faculty, "Union - Nikola Tesla University", Belgrade, Serbia \\ ${ }^{2}$ Faculty of Entrepreneurial Business, "Union - Nikola Tesla University“, Belgrade, Serbia \\ ${ }^{3}$ The College of Tourism, Belgrade, Serbia \\ nebojsazakic@gmail.com
}

\section{Professional Paper doi:10.5937/jouproman5-13748}

\begin{abstract}
Six Sigma is a well-structured and proven methodology for improving organizational performance. It helps achieving the goals of the organization through the use of project-driven approach. The implementation of Six sigma approach depends on proper identification and selection of projects, moreover, the selection of right Six sigma projects is one of the critical success factors of six sigma efforts. The paper provides the sources for the identification of potential projects, top down and bottom up approaches, the process of selection of projects, guidelines that assist the selection of appropriate projects, selection criteria which must be precisely chosen in accordance with the objectives, needs and capabilities of the organization as well as sophisticated techniques and tools recommended in the literature for the selection of projects.
\end{abstract}

Key words: Six Sigma, Project Identification, Project Selection

\section{Introduction}

Performance improvement is an integral part of business strategy of numerous companies in production and service sector. Over the last decades many different process improvement methodologies have emerged such as Total Quality Management, Six Sigma, Lean Initiatives etc. which initiated the development of numerous tools and techniques. This paper focuses on Six Sigma approach which is, as Pande et al. (2000) define it, a comprehensive and flexible system for maintainance and maximization of business sucess rate. Six Sigma is directed towards understanding the clients` needs, disciplined use of facts and figures along with statystical analyses and diligent work in the field of management, improvement and innovation in business processes.

In fact Six Sigma represents an extension of other approaches such as Statistical Process Control and Total Quality Management. Similar to most other process improvement strategies Six Sigma focuses on customers' satisfaction as its main goal. A new quality it offers is rigorous approach, shortened time scope for achieving benefits, higher intensity of interventions, the overall amount of change and perfection in the result. Organization performances are measured by Sigma level of the processes so that the number of flaws of most organizations are 4 Sigma i.e. 6, 200 defects/million units. Six Sigma approach aims at decreasing the flaws to only 3,4 defects/million units. Thus, it is perfectly clear that Six Sigma is rigorous, focused and highly effective implementation of proven quality principles and techniques which aims for virtually error free business performance (Pyzdek,2003).

Six Sigma is a multidymensional structured approach which has proven to be effective in process improvement, minimalization of flaws, reduction of process variability, cost reduction, increase in customer satisfaction and profit. 
Based on its sucessful implementation in Motorola, General Electrics and other companies which were pioneers of this approach, Six Sigma has become very popular in companies throughout the world and almost all production and service industries. The benefits of Six Sigma are largely presented in literature (Hahn et al., 1999; Robinson, 2005; Dhiraj, Deepak 2014; etc.). However, there is a significant number of companies which have not been sucessful in implementation of Six Sigma paradigm (Ahadian, Abadi, 2012). Certainly Six Sigma is not a remedy for all organizational problems. Six Sigma is appropriate when the focus is on efficiency and when environment change rate is not high. Six Sigma is not a suitable approach when a company is facing radical changes (Mellat Parast, 2011).

The paper is organized as follows. After the introduction, the first part focuses on Six Sigma projects and critical sucess factors. The central part of the paper comprises sections dedicated to potential projects identification and Six Sigma projects selection, while the paper ends with a conclusion.

\section{Six Sigma projects and critical sucess factors}

Systematic changes in organizations are realized through projects. According to Project Management Institute-PMI (2013), a project is a transient endevour undertaken in order to create a unique product, service or result. Association for Project Management-APM (2012) defines project as a unique, transient endeavour, undertaken to achieve planned objectives. In line with their main features projects are: goal-oriented - a project has defined goals that are to be achieved; limited in duration - projects are temporary with clearly defined beginning and end; unique - projects are unique and unrepeatable endevours; different activities and tasks - projects can be simple or complex comprising different activities and tasks which lead to its goals; limited resources there are limited human, financial, material and information resources in realization of activities and tasks; risk - projects can have low or high risk rate, while risk factors can be external or internal.

Even before Six Sigma approach was invented the former initiatives for process and quality improvement projects had been recognized as tools for systematic change. Gryna (Juran, Gryna, 1988) observes the following about projects: inclusion of projects on official priority lists ensures necessary budget, equippment and personnel; projects secure that the atmosphere of defensiveness and blame is converted into constructive action; projects provide cost reduction and increase in quality and customer satisfaction; all improvements are made through projects on one-at-a-time basis and solely in that way. Six Sigma approach is based on improvements through projects on one-ata-time basis which are combined with full-time or part-time projects led by experts or managers who, as inspired by karate terminology, are called black or green belt masters.

Key Six Sigma methodology comprises five phases of DMAIC methodology( D define, $\mathrm{M}$ - measure, A - analyze, I improve, $\mathrm{C}$ - control) which is used to improve the existing processes. In the first phase, the goal and scope of a problem are defined and problems identified. In the second phase, the data about the existing process are gathered through appropriate methodology and measurements. In the third phase the process is analyzed so as to determine root causes of the problem. The fourth phase consists of process improvementh through elimination of root causes of a problem, while the solutions require creative effort to use the analysis and conclusions from the previous stages. 
In the fifth and last phase the implementation of the solution is controlled and the improved process is supervised and monitored.

According to Linderman, Chandraskaran (2010) DMAIC methodology can be considered a meta-routine which allows the change of existing processes and routines. DMAIC is in Six Sigma metaroutine in most projects (Marzagalo, Carvalho, 2016).

Implementation of Six Sigma projects in the three decades of its existence with varying rate of success made researchers identify the critical success factors of Six Sigma approach. The idea of identifying critical success factors as a basis for directing managers towards what they really need to pay attention to in order to succeed was popularized by Rockart (1979). According to Rockhart, Bullen (1981) critical factors of success are a limited number of areas in which favourable results will enable sucessful competetive performances in a particular organization. Key factors of success focus on the most important areas and go to the core of the problem comprising the content issues(what should be achieved) and process issues(how to achieve it).

Exploring successful and less successful implementation of Six Sigma in companies the reasearchers identified critical factors of Six Sigma initiatives among which are the following: leadership - involment and commitment of the top management; understanding of Six Sigma methodology, tools and techniques; connecting Six Sigma with business strategy; connecting Six Sigma with customers; connecting Six Sigma with human resources; connecting Six Sigma with suppliers; selection of six sigma projects; project management abilities; coordination and team work; communication; organizational structure and capacity of resources; training; cultural change; a system of measuring, rewarding and monitoring projects (Banuelas Coronado, Antony, 2002; Shanmugaraja et al., 2011). Selection of projects as one of the main critical success factors of Six Sigma efforts has been recognized by a number of researchers (Mc Adam, Evans, 2004; Ho et al., 2006; Yang et al., 2008; Brun, 2011; Margazalo, Carvalho, 2016).

\section{Identification of Six Sigma projects}

Potential Six Sigma projects may be identified through various sources. According to Pande et al. (2000) the sources of ideas for projects may include external, internal/external and internal sources. External sources relate to the problems and opportunities to satisfy customers' demands, respond to market trends or competitors activities. Four categories that usually belong to this kind of sources are usually listed as: the voice of customer, the voice of market, the voice of supplier and comparison with competition. Internal/external sources relate to identifying challanges that a certain business faces in the definition and achievement of its strategic goals. Internal sources relate to the problems and opportunities percieved within an organization and its processes and are labelled the voice of process and the voice of employees.

Marques et al. (2014) identify the following four kinds of sources which they put into a four area scheme: external, internal, retroactive and proactive resources. Internal sources relate to the data generated within a company which is either available or proactively gathered. External sources include the data outside of the company which is eather available or proactively gathered. Retroactive sources are existing or historical data within a company or outside the company. 
Proactive sources may be found inside or outside of a company and they are typically not readily available so they require certain proactive activities in order to reach them. Internal retroactive sources of data may be performance data (internal processes, finances etc.), internal technical and commercial reports, test and inspection results etc. External retroactive sources may include customer complaints and demands, the data extracted from customer surveys, the results of supplier and subcontractor ratings etc. Proactive internal sources include the data from brainstorming sessions, personnel suggestions, the results of self assessment relating to internal factors according to a certain model of excellence etc. External proactive sources can be research or development projects in partnership with scientific research institutions, third party checks, the results of self assessment (external factors) according to a particular model of excellence etc.

Generally speaking there are two ways of generating Six Sigma projects: top-down and bottom-up method. Top-down method is usually linked to big "black belt" projects (Basu, Wright, 2003) and is closely connected with business strategy and customers' demands. According to this method senior executives analyse the main problems and performance goals and suggest strategic improvement projects which represent a base from which the Six Sigma champions and teams can identify the processes and features which are critical for success and recognize specific opportunities for improvement. A significant advantage of this approach is the complience of Six Sigma projects with strategic and corporate goals. One of the disadvantages of this approach is that some projects of this kind tend to be too large to be completed in four or six-month time span which is a usual practice for Six Sigma projects.
According to bottom-up method the ideas for Six Sigma projects are developed within the operational level of organization and the employees are directly involved into project initiatives (Schroeder, et al., 2008). The projects of this kind often include cost reduction, solution to specific problems of quality or the improvement of process flow, they are usually smaller in range and easier to complete. Bottom up method depends on networking within organization. The main disadvantage of this method is that such projects are less directly connected with the main strategic goals which may cause their lower rate of visibility and senior management support.

Literature gives an advantage to top-down approach (Harry, Schroeder, 2006). According to Lynch, Beth Soloy (2014) bottom-up method will be probably used in the early stages of implementation of Six Sigma approach when the systemic process has not been developped yet. From the point of view of top-down method the right to decide to initiate Six Sigma project belongs to seniour management and each project is expected to have a clear connection with the business strategy. According to Larson, Gray (2011) the initial project identification should include the following necessary activities: (1) reconsidering the mission of the organization; (2) establishing long-term goals and objectives; (3) the analysis and development of strategies for achieving desirable goals; and (4) the establishing of portfolio of project choice. The final list of projects is subject to further evaluation and selection.

\section{Selection of Six Sigma projects}

Selection of projects is a process of evaluation of several indiviadual projects or project groups and the choice of a certain set of them in order to achieve goals of an organization (Meredith, Mantel, 2003). 
The selection of suitable projects is one of main critical factors for the success of Six Sigma implementation. The selection of Six Sigma projects has strategic importance (Schroeder, et. al., 2008) and significant implications that influence the whole organization. It is one of the central management mechanisms of Six Sigma approach which should allocate resources effectively and set priorities for Six Sigma endevours. According to Antony (2004), selection of the right projects is one of the key factors in early success and long-term acceptance of Six Sigma approach in an organization. Inappropriate selection of projects generates various kinds of problems such as (Kendall, Rollins, 2003): too many active projects, wrong projects, projects which are not connected with the strategy and an unbalanced project portfolio. If the selection of projects is systematically careless and irresponsible all Six Sigma effort can be doomed to failure (Pyzdek, 2003).

The process of project selection generally comprises the following steps: (1) compiling a list of potential project candidates (potential projects) - the data about listed projects should be prepared in an appropriate format and completed; (2) establishing criteria for project selection the criteria should be established according to the predefined requirements and in complience with the mission and; prioratization of projects - the selected projects are assessed according to the established criteria in order to achieve a rated result; (4) the choosing of projects at this stage the best rated projects are chosen, and a case study is developped in order to get the necessary approval of the top management.

Project selection is, as Kumar et al. (2007) point out, one of the most important but also the most difficult tasks of Six Sigma approach. According to Banuelas, et al., (2006) Six Sigma projects often fail because of an inappropriate selection. Due to the importance and complexity of the task it is clear why this issue draw the attention of a large number of researchers. We can find various guidelines for Six Sigma project selection by different authors, among which the following can be selected:

- Project should be clearly connected with the strategy and organizational goals (Pyzdek, 2003; Snee, Hoerl, 2003; Antony, 2004);

- The recognized problem should have utmost importance for a business in terms of process performance improvement and financial impact (Snee, Hoerl, 2003; Montgomery, 2004);

- The scope of the project should not be too big, and it is highly recommended to complete it in four to six months (Snee, Hoerl, 2003; Antony, 2004; Montgomery, 2004);

- Project goals should be clear, specific, achievable, realistic and measurable, with high probability of success (Pande et al., 2000; Antony, 2004);

- The criteria of project selection should be based on a realistic and correct metrics (Pande et al., 2000; Harry, Schroeder, 2006);

- The importance of projects should be made clear in the organization, all those involved should be committed to the project success and have thorough knowledge of Six Sigma techniques and tools (Snee, Hoerl, 2003);

- A feeling of urgency should be created in line with the priority of Six Sigma projects (Antony, 2004); 
- Projects should have top management support, including provision of resources, barrier overcoming and sustainability over time (Snee, Hoerl, 2003; Pyzdek, 2003).

The definition of criteria for project selection requires a precise analysis. According to Pande et al. (2000) the criteria can be grouped into three categories: (1) business benefits or results; (2) feasibility criteria (3) organizational impact. In the category of business benefits or results we can include: impact on external customers and customer requirements, impact on business strategy and competitive position, impact on core competences, financial impact, urgency, trend and sequence or dependence. The criteria of feasibility are: resource requirements, available expertise, complexity, success probability and the support of key groups in an organization. The criteria of organizational impact include: learning benefits and cross functional benefits.

Adebanjo et. al (2016) list the following criteria: 1) feasibility; (2) financial impact; (3) impact on the customer; (4) impact on operation goals; (5) impact on the employees and (6) impact on the supplier.

Yousefi et al. (2016) select the following criteria: (1) project cost; (2) reduction of low quality costs; (3) project implementation period; (4) customer satisfaction; (5) the increase of Sigma level (Sigma quality) and (6) top management responsibility. Literature brings other criteria as well. An organization cannot use all the criteria in process selection. It is necessary to establish a limited number of criteria which are the most relevant in a particular situation. The criteria should be well adjusted to the needs, abilities and goals of an organization (Kelly, 2002).

Selection of right Six Sigma projects is a complex process which may include different sophisticated methods, tools and techniques. The relevant literature cites quantitative and qualitative methods used for the decision-making in Six Sigma projects. Pyzdek (2003) and Thomas (2003) recommend Pareto analisys and Pareto priority index (PPI). Pyzdek (2003) uses a Theory of Constraints (TOC). Kelly (2002) proposes Project Selection Matrix while Adams et al. (2011) suggest Project Ranking Matrix. A number of authors (Banuelas, Antony, 2007; Kendrick, Saati, 2007; Su, Chou, 2008 i dr.) apply Analytic Hierarchy Process (AHP). Nourpanah et al. (2011) integrate Group Analytic Hierarchy Process (GAHP) and Linear Programming (LP). Ortiz et al. (2015) write about the application of Analytic Network Process(ANP) methods and Decision Making Trial And Evaluation Laboratory (DEMATEL) in the selection of projects. Shanmugaraja et al. (2012) develop a model of project selection based on Quality Function Deployment (QFD). Relevant literature brings a number of other techniques recommended for the selection of Six Sigma projects. However, in practice the use of sophisticated methods and techniques is limited and numerous organizations still select projects ad hoc.

\section{Conclusion}

Six Sigma is a rigorous and disciplined approach to performance improvement. The benefits of Six Sigma are extensively represented in literature. Six Sigma is a proven and effective management strategy, implemented by a large number of companies in the world. Six Sigma is a project-led approach and projects are an integral part of Six Sigma initiatives. 
Identification and selection of Six Sigma projects is a core component of a systemic effort to improve performance and one of the key factors of Six Sigma implementation success. Identification and selection Six Sigma projects is a complex task and remains one of the major challanges that companies face. Organizations should adopt systemic methods of potential Six Sigma project identification and they should master sophisticated methodology, techniques and tools for project selection in order to carry out Six Sigma projects which would bring the highest rate of benefit to the organization and which would be best alligned with goals and abilities of a company.

\section{Reference}

[1] Pyzdek, T. (2003). The six sigma hanbook. McGraw-Hill, New York.

[2] Hahn, G. J., Hill, W. J., Hoerl, R. W., Zinkgraf, S.A. (1999). The impact of six sigma improvement - a glimpse into the future of statistics. The American Statistician, 53(3), 208-215.

[3] Robinson, B. (2005). Build a managemet system based on six sigma. ASQ Six Sigma Forum Magazine, 5(1), 28-34.

[4] Dhiraj, K., Deepak, K. (2014). A Review of Six Sigma Approach: Methodology, Obstacles and Benefits. Global Journal of Engineering, Design \& Technology, 3(4):1-5.

[5] Ahadian, B., Abadi, A. G. M. (2012). Six Sigma Pilot Project Selection Using an MCDM Approach. Management Science and Engineering, 6(1), 34-43.

[6] Mellat Parast, M. (2011). The effect of Six Sigma projects on innovation and firm performance. International Journal of Project Management, 29, 45-55.

[7] Project Management Institute (2013). A Guide to the Project Management Body of Knowledge (PMBOK@Guide) Fifth edition, Newton Square.

[8] Managing Change in Organizations: A Practical Guide. Newton Square.
[9] Association for Project Management (2012). APM Body of Knowledge, 6th edition. Princes Risborough.

[10] Juran, J. M., Gryna, F. M. (1988). Juran's Quality Control Handbook. 4th edition. McGraw-Hill, New York.

[11]Linderman, K., Chandraskaran, A. (2010). The progress and exchange of knowledge in operations management. Journal of Operations Management, 28, 357-366.

[12] Marzagalo, D. S. L., Carvalho, M. M. (2016). Critical success factors for Six Sigma projects. International Journal of Project Management, 34, 1505-1518.

[13] Rockart, J. F. (1979). Chief executives define their own data needs. Harvard Business Review, 23)4), 238-241.

[14] Rockhart, J. F., Bullen, C. (1981). A primer on critical factors. Center for Information Szstem Research Working Paper No. 69. Sloan School of Management, MIT, Cambridge.

[15] Banuelas Coronado, R., Antony, J. (2002). Critical success factors for the successful implementation of Six Sigma projects in organizations. The TQM Magazine, 14(2), 92-99.

[16] Shanmugaraja, M., Nataraj, M., Gunasekaran, N. (2011). Six sigma project selection via quality function deployment. International Journal of Productivity and Quality Management, 10(1), 85-111.

[17] Mc Adam, R., Evans, A. (2004). The organizational contextual factors affecting the implementation of Six Sigma in a high technology mass-manufacturing environment. International Journal of Six Sigma and Competitive Advantage. 1(1), 29-43.

[18]Ho, S., Xie, M., Goh, T. (2006). Adopting Six Sigma in higher education: some issues and challenges. International Journal of Six Sigma and Competitive Advantage, 2(4), 335-352.

[19] Yang, K., Yeh, T., Pai, F., Yang, C.-C. (2008). The analysis of the implementation status of Six Sigma: an empirical study in Taiwan. International Journal of Six Sigma and Competitive Advantage, 4(1), 60-80. 
[20] Brun, A. (2011). Critical success factors of Six Sigma implementations in Italian companies. International Journal of Production Economics, 131, 158-164.

[21] Marques, P. A., Saraiva, P. M., Requeijo, J. G., Guerreiro, F. F. (2014). Six Sigma Life Cycle. In: Henriques, E., Pecas, P., Arlindo, S. (Eds.). Technology and Manufacturing Process Selection. Springer-Verlag, London.

[22] Basu, R., Wright, J. W. (2003). Quality Beyond Six Sigma. Routledge, Abingdon.

[23] Schroeder, R. G., Linderman, K., Liedtke, C., Choo, A. S. (2008). Six Sigma: Definition and underlying theory. Journal of Operational Management, 26, 2008.

[24] Harry, M., Schroeder, R. (2006). Six Sigma: The Breaktrough Management Strategy Revolutionizing The Worlds Top Corporations. Random House, New York.

[25]Lynch, D. P., Beth Soloy, M. (2014). The Project Champion's Role. Quality Engineering Application \& Research, 2014-2197; 1-23.

[26] Larson, E. W., Gray, C. F. (2011). Project Management: the managerial process. McGraw-Hill, New York.

[27] Meredith, J. R., Mantel, S. J. (2003). Project Management: A Managerial Approach. Wiley, New York.

[28] Antony, J. (2004). Six Sigma in the UK service organizations: results from a pilot survey. Managerial Auditing Journal, 19(8), 1006-1013.

[29] Kendall, G. I., Rollins, S. C. (2003). Advanced project portfolio management and the PMO: Multiplying ROI at warp speed. J. Ross Publishing, Boca Raton.

[30] Kumar, U.D., Saranga, U., RamirezMarquez, J.E., Nowicki, D. (2007). Six Sigma project selection using data envelopment analysis. The TQM magazine, 19(5), 419-441.

[31] Banuelas, R., Tennant, C., Tuersley, I., Tang, S. (2006). Selection of six sigma projects in the UK. The TQM Magazine, 18(5), 214-527.

[32] Snee, R. D., Hoerl, R. W. (2003). Leading Six Sigma: A Step-by-step Guide Based on Experience with GE and Other Six
Sigma Companies. Financial Times Prentice Hall, Upper Saddle River.

[33] Montgomery, D. C. (2004). Selecting the Right Improvement Projects. Quality and Reliability Engineering International, 20(7): iii-iv.

[34] Adebanjo, D., Samaranayake, P., Mafakheri, F., Laosirihongthong, T. (2016). Prioritization of Six-Sigma project selection: A resource-based view and institutional norms perspective, 23(7), 1983-2003.

[35] Ortiz, M. A., Felizolla, H. A., Isaza S. N. (2015). A contrast between DEMATELANP and ANP methods for six sigma project selection: a case study in healthcare industry, BMC Medical Informatics and Decision Making, 1-12.

[36] Yousefi, A., Hadi-Vencheh, A. (2016). Selecting Six Sigma projects: MCDM or DEA? Journal oF Modeling in Management, 11(1), 309-325.

[37] Kelly, W. M. (2002). Three Steps To Project Selection. Six Sigma Forum Magazine, 2(1), 29-32.

[38] Adams, C., Gupta, P., Wilson, C. (2011). Six Sigma Deployment. Routledge, Abington.

[39] Thomas, P. (2003). The Six Sigma Project Planner. McGraw-Hill, New York.

[40]Banuelas, R., Antony, J. (2007). Application of Stochastic Analytics Hierarchy Process within a Domestic Appliance Manufacturer. Journal of the Operational Research Society, 58(1), 2910.

[41] Kendrick, J. D., Saaty, D. (2007). Use Analytic Hierarchy Process For Project Selection. Six Sigma Forum Magazine, 22-29.

[42] Su, C.-T., Chou, C.-J. (2008). A systematic methodology for the creation of Six Sigma projects: A case study of semiconditor foundry, Expert Systems with Applications, 34, 2693-2703.

[43] Nourpanah, P., Ansary, N., Nourpanah, R., Amini, S. (2011). Selection Six Sigma Project Use Gahp-Lp. Australian Journal of Basic and Applied Sciences, 5(12): 1917-1922. 